\title{
BARRIERS TO IMPLEMENTATION OF BUSINESS PROCESS GOVERNANCE MECHANISMS
}

\author{
ARKADIUSZ JURCZUK
}

\begin{abstract}
A B S T R A C T
One of the main challenges in implementing process-oriented management is establishing a governance mechanism in the organisation. It creates a coherent framework for the execution, management and perception of business processes, which is the foundation of consistent Business Process Management (BPM). Process governance (PG) refers to an organisation's ability to manage its relationships with all process stakeholders and support the value chain for its customers. Its implementation involves establishing process regulation mechanisms and stakeholder-oriented criteria to support prioritisation, cascading, and change management within BPM initiatives. A review of the domain literature reveals that while process governance has been discussed from several but separated perspectives (strategy, business roles, performance, and maturity), only a few studies identify and synthesise the barriers to its implementation in organisations. The paper mainly aims to identify and classify the key barriers to the implementation of process governance. The author's approach refers to the six core elements of Business Process Management capability and process governance frameworks. Research results confirm that most process governance barriers polarise around the competence gaps of the process stakeholders and the immaturity of the process-oriented culture of companies. Another significant group of constraints to process governance arises from the existing organisation's structure. They are mainly related to the proper division of responsibilities and a weak position or the lack of BPM centres of excellence. The research contributes to the literature on management by identifying potential barriers to business process governance that constrain BPM initiatives. The identified PG challenges can provide a basis for developing a theoretical framework for Business Process Management and models for BPM success factors.
\end{abstract}

KEY WORDS

business process management, process governance, success factors, barriers

10.2478/emj-2021-0029 pages: $22-38$
Corresponding author

Arkadiusz Jurczuk

Bialystok University of Technology, Poland ORCID 0000-0003-2994-8180 e-mail: a.jurczuk@pb.edu.pl

\section{INTRODUCTION}

Business Process Management (BPM) is becoming one of the leading approaches to governing contemporary organisations. It is confirmed by the market value of IT services and solutions in this area. It is predicted that the value of the global BPM market may increase by about $10 \%$ by 2025 , reaching USD 14-15 billion (Markets and Markets, 2020). Furthermore, more than $70 \%$ of enterprises (Harmon \& Garcia, 2020) have seen a significant increase in the

Jurczuk, A. (2021). Barriers to implementation of business process governance mechanisms. Engineering Management in Production and Services, 13(4), 22-38. doi: 10.2478/emj-2021-0029 
BPM interest over the past two years. This is due to the growing need to respond more quickly to the changing market and customer expectations. It is also linked to the increasing effort to automate and robotise processes, as well as the perception of the business process itself as a service.

Although there are differences in specific BPM definitions (Jurczuk, 2019), it is generally considered a process-oriented management philosophy that uses modern IT systems and technologies to help manage the entire lifecycle of business processes (Elzinga et al., 1995). Due to the holistic approach, it addresses the area and challenges of organisational management related to both the business itself and the technologies driving its growth. The most frequently highlighted tangible effects of BPM implementation include cost reduction and improved quality of customer service, translating into improved competitiveness of the organisation (Harmon \& Garcia, 2020). However, achieving specific benefits from implementing BPM is associated with the need to establish a formalised governance framework. They are aimed at developing situationally relevant organisations' structures, establishing a system of measures and monitoring processes and introducing an explicit division of roles and responsibilities for the functioning of processes in the organisation. Their establishment may lead to a tangible improvement in communication effectiveness and consistency of decision-making in the organisation (Markus \& Jacobson, 2015).

Despite the well-established and mature nature of the BPM methodology (Huy et al., 2010), the success rate of BPM initiatives is relatively low and often stays below 50 \% (Iqbal et al., 2015; Thennakoon et al., 2018, Funke \& Syed, 2019). With that said, the success rate for large BPM projects (Syed et al., 2018) and those requiring collaboration between different functional units of the organisation is significantly lower (Spanyi, 2010). This may be due to an overlooked role of individual factors constituting BPM (Malinova et al., 2014). These include top management support, strategy alignment, methodology, clear responsibilities, culture, measurement and monitoring, and IT alignment (Trkman, 2010; do Amaral Castro et al., 2020). From the perspective of establishing and operating organisational governance mechanisms, this may be related to the lack of a comprehensive process governance (PG) approach (de Boer, 2015; Bandara et al., 2019). This factor is recognised as a key determinant of the success of BPM projects and initiatives (Kirchmer et al., 2015; Hernaus et al., 2016; Czarnecki, 2018). Moreover, PG also supports the management of organisational activities, spanning different functional areas (Spanyi, 2010; Hernaus et al., 2016). According to Scheer and Klueckmann (2009), governance mechanisms play an important role in facilitating the transition from unstructured to structured BPM. The pillars and success determinants of process governance are mainly roles and responsibilities, metrics, standards and the methodology (Jeston \& Nelis 2008; Markus \& Jacobson, 2015; Ensslin et al., 2017).

While the critical success factors of BPM are relatively well described in the literature (Trkman, 2010; Bai and Sarkis, 2013; do Amaral Castro et al., 2020), the problem of process governance (PG) barriers/ constraints is not widely discussed in the literature (Spanyi, 2010; Valenca et al., 2013; Santana et al., 2011; Doyle \& Seymour, 2020). A literature review on BPM did not reveal many papers that comprehensively considered barriers associated with establishing and operating process governance. The ongoing research in the area of process governance is mainly concerned with frameworks (Hove et al., 2015; Markus \& Jacobson, 2015; Doebli, 2011; Kirchmer, 2017), the functioning of the process competence/excellence centre (Jesus et al., 2015; Bitkowska, 2018; Bandara et al., 2019), the role of the process owner (Hernaus et al., 2016; Danilova, 2018, Hrabal et al., 2020), and digital transformation (Fisher et al., 2020; Kerpedzhiev et al., 2021). Despite the multifaceted nature of these studies, their authors clearly indicate the relevance of process governance and the need for a further and more comprehensive exploration of this issue due to the changing and situational conditions of BPM implementation. The validity of exploring this issue is confirmed on the one hand by the growing interest in simplifying the activities of enterprises and on the other by the still relatively low success rates of BPM undertakings.

Therefore, the aim of the article is to identify key elements and retrospectively analyse barriers to establishing process governance in an enterprise. On the basis of the conducted literature study, including the results of post-implementation evaluations, the role of individual elements was indicated, and an attempt was made to classify the barriers to establishing PG using the Six Core Element BPM model and the key BPM process governance frameworks. The contribution of this article is a structured characterisation of the barriers and the development of the BPM capability framework in the area of process governance.

The remaining part of the article is organised as follows. The second part presents the theoretical background on process governance. The third part is 
devoted to the identification and discussion of PG barriers based on the results of literature studies.

On this basis, a synthetic approach to their typology is proposed. The fourth part formulates the final conclusions and recommendations concerning the PG implementation in an enterprise, research limitations and avenues for future efforts.

\section{Process governance - THEORETICAL BACKGROUND}

Contemporary organisations are becoming increasingly aware that competitiveness improvement is possible by changing the orientation from functions to processes. Consequently, it leads to concentrating the organisation on process-based approaches, including Business Process Management (Harmon \& Garcia, 2020). The Association of Business Process Management Professionals (ABPMP) defines BPM as a disciplined approach to identification, design, execution, documentation, measurement, monitoring and control of business processes to achieve consistent, focused results corresponding with the strategic objectives of the organisation. The key role of BPM is to coordinate the undertaken activities to maintain the consistency of the organisation's processes and the situational alignment of its tools and methods (ABPMP, 2013). This results in increased organisational performance through systematic and end-toend operational improvements and business agility (Korhonen, 2007). Many researchers (Spanyi, 2010; Markus \& Jacobson, 2015; Bandara et al., 2019) emphasise that achieving specific benefits from successful BPM initiatives requires a formalised governance framework.

The understanding of the general concept and role of process governance in the domain literature is relatively consistent (Ensslin et al., 2017). The primary PG objective is to ensure that BPM is implemented effectively to meet the expectations of the organisation and its stakeholders (Kirchmer, 2015). Process governance generally refers to an organisation's ability to manage relationships with all process stakeholders and value creation for their internal/external customers. It is defined as a set of guidelines and resources that an organisation uses to facilitate collaboration and communication when it undertakes process initiatives (Hove et al., 2015). Process governance was similarly characterised by de Bruin (2009), pointing out that its key elements are: establishing appropriate and transparent responsibility, establishing rules for making decisions, and rewards and motivation. Spanyis definition (2010) of process governance also directly indicates its role to provide appropriate structures, metrics, roles and responsibilities to measure, improve and manage the performance of a company's end-to-end business processes. It is also emphasised that governance mechanisms must be consistent and established for the entire BPM activities and individual business processes (Rosemann \& Vom Brocke, 2010).

Process governance is achieved primarily thanks to the use of acceptable, clearly understandable rules and regulations that create a consistent framework for the performance, management and perception of business processes. A mechanistic or organic approach is used to establish and implement them (Braganza \& Lambert, 2000; Markus \& Jacobson, 2015). In the first case, creating the foundations of governance is based on formal documents containing a strategy, business plan and descriptions of the roles and responsibilities of process owners/leaders. All decisions, agreements, and regulations are formally recorded. On the other hand, with the organic approach, leaders, by providing information about decisions and changes (informal personal interactions), strive to fully understand the external conditions that determine the functioning of the organisation, its goals and strategy. However, in relation to these approaches, it is worth emphasising that they should be treated as complementary methods. The formal approach does not guarantee capturing and describing all aspects ensuring the desired level of governance, while the informal approach does not create a permanent basis for BPM (Braganza \& Lambert, 2000; Markus \& Jacobson, 2015). Organisations try to adapt various appropriate forms and a framework of process governance and their conditions of BPM implementation (Bhat \& Fernandez, 2007; de Boer et al., 2015; Bandara et al., 2019). However, no one universal established approach exists to implementing PG and/or there is no established structure and scope for such a project (Doebli et al., 2011; Valenca et al. 2013; Czarnecki, 2018; Hernaus et al., 2019).

Based on the literature review, an attempt was made to identify the essential elements and capabilities of an organisation that constitute the establishment of process governance. Table 1 presents a proposal for a synthetic set of core elements constituting process governance together with a reference to research results confirming their relevance. Considering the indicated dissimilarity and specificity of certain groups of PG elements (Braganza \& Lambert, 
Tab. 1. Generic elements of process governance mechanisms

\begin{tabular}{|c|c|c|c|}
\hline PG APPROACH & $\begin{array}{l}\text { PROCESS GOVERNANCE } \\
\text { CORE ELEMENTS }\end{array}$ & RELATED ELEMENTS & $\begin{array}{c}\text { REFERENCE } \\
\text { (SELECTED EXAMPLES) }\end{array}$ \\
\hline \multirow{2}{*}{ 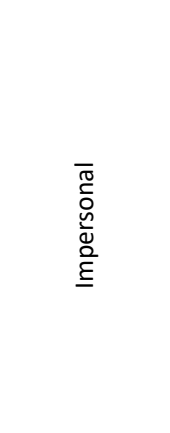 } & $\begin{array}{l}\text { Methodology and } \\
\text { process management } \\
\text { standards }\end{array}$ & $\begin{array}{l}\text { BPM frameworks } \\
\text { BPM Life-Cycle } \\
\text { Process documentation } \\
\text { Process architecture }\end{array}$ & $\begin{array}{l}\text { Richardson, } 2006 \\
\text { Bhat \& Fernandez, } 2007 \\
\text { DeBruin, } 2009 \\
\text { Jeston \& Nellis, } 2014 \\
\text { Rosemannn \& Vom Brocke, } 2015 \\
\text { Jurczuk, } 2019\end{array}$ \\
\hline & $\begin{array}{l}\text { Measurement and } \\
\text { performance }\end{array}$ & $\begin{array}{l}\text { Process metrics } \\
\text { Measurement system } \\
\text { Performance linkage }\end{array}$ & $\begin{array}{l}\text { Spanyi, } 2010 \\
\text { Doebeli et al., } 2011 \\
\text { Kohlbacher \& Gruenwald, } 2011 \\
\text { Rosemannn \& Vom Brocke, } 2015\end{array}$ \\
\hline \multirow[b]{2}{*}{$\begin{array}{l}\bar{\pi} \\
\overline{0} \\
\frac{n}{0} \\
\alpha\end{array}$} & $\begin{array}{l}\text { Roles and responsibili- } \\
\text { ties }\end{array}$ & $\begin{array}{l}\text { Process owner } \\
\text { BPM-related roles }\end{array}$ & $\begin{array}{l}\text { Bhat \& Fernandez, } 2007 \\
\text { Davis \&Brabänder, } 2007 \\
\text { Spanyi, } 2010 \\
\text { Vom Brocke et al., } 2014 \\
\text { von Rosing et al., } 2015 \\
\text { Danilova, } 2018 \\
\text { Hrabal et al., } 2020\end{array}$ \\
\hline & Cooperation bodies & $\begin{array}{l}\text { Process improvement and governance } \\
\text { charters/teams } \\
\text { BPM Centre of Excellence } \\
\text { (or Competence Centre or BPM Office) }\end{array}$ & $\begin{array}{l}\text { Bhat \&Fernandez, } 2007 \\
\text { Davis \& Brabänder, } 2007 \\
\text { Jeston \& Nelis } 2008 \\
\text { Vom Brocke et al., } 2014 \\
\text { von Rosing et al., } 2015 \\
\text { Markus \& Jacobson, } 2015 \\
\text { Rahimi et al., } 2016 \\
\text { Bitkowska, } 2018 \\
\text { Bandara et al., } 2019\end{array}$ \\
\hline
\end{tabular}

2000; Spanyi, 2010; Markus \& Jacobson, 2015; Danilova, 2018), their division into two categories representing impersonal and personal approaches to process governance was proposed. As Markus \& Jacobson (2015) emphasised, impersonal or institutional mechanisms are advisable when business processes cross the boundaries of the organisation or its business units. At the same time, they are rarely effective without personal governance mechanisms that consider the need for coordination, process control and collaboration provided by the BPM leader, process owners and employees representing specific process roles (Vom Brocke et al., 2014).

The group of elements of the impersonal approach includes methodology and standards, measurement and performance. The personal PG mechanism includes issues related to the definition of process roles and the appropriate division of responsibilities. Moreover, within this element, the establishment of process teams and the Business Process Management Centre of Excellence (BPM CoE) were deliberately highlighted. In the domain literature, such a centre is also referred to as BPM Competence Centre or BPM Office. The distinction of this PG element is due to the establishment of the BPM CoE, which is crucial for the division of responsibilities and the communication and decision-making process related to BPM initiatives (Richardson, 2006; Davis \& Brabänder, 2007; Jeston \& Nelis 2008, Bitkowska, 2018).

To verify and realign the identified process governance core elements, they were matched with selected models and frameworks that have been referred to most frequently by other researchers analysing BPM issues (several citations in Google Scholar). The Business Process Management Six Core Elements model (Rosemann \& Vom Brocke, 2010) was taken as the generic model for the PG capabilities of organisations. This is because it represents the widely accepted critical success factors of BPM. These are strategic alignment, governance, methods, information technology, people, and culture. For each of the elements of the model, Capabilities Areas are defined, which refer to the capabilities of the organisation that are crucial for the success of a BPM imple- 
mentation. According to the accepted assumptions of the BPM Six Core Elements model, the governance factor represents activities and guidelines related to establishing appropriate and clear accountability in terms of roles and responsibilities for the different levels of BPM and designing decision-making and reward processes to guide process activities (Rosemann \& De Bruin, 2005). The process governance frameworks proposed by Kirchmer (2017), and Braganza \& Lambert (2000) were also used to assess the relevance of process governance core elements. They provide guidelines related to the establishment of PG in an organisation complementing the BPM Six Core Elements model. They represent the integration perspective of strategy, business processes and accountability (Braganza \& Lambert, 2000) and the enterprise-specific execution of BPM (Kirchmer, 2017). The relevance analysis of the PG elements also considered the BPM guidelines developed by Jeston \& Nelis (2014).

The core elements identified from the literature review are reflected in the selected process governance frameworks (Table 2). Two elements, "measurement and performance" and "roles and responsibilities", are directly included in all models and guidelines. BPM methodology and standards are included in the BPM Six Core Elements model (Rosemannn \& Vom Brocke, 2015) and the guidelines developed by Jeston \& Nelis (2014). In the analysed studies, the element related to establishing process teams and changes in the organisation's structure is implicitly indicated as the key to process governance. It is mostly considered in the context of defining roles and responsibilities, i.e., teamwork, distributed leadership, and empowerment.

In the investigated frameworks, the element related to the establishment of the BPM Centre of Excellence and the associated changes in the organisation's structure is usually not isolated. This factor is considered in the context of business roles and responsibilities. However, the analysis of the expert opinions and the results of the research carried out so far justify developing the existing frameworks (Table 1) and distinguish the governance bodies as a fourth and key element constituting the establishment of PG in the organisation. Due to the role of the BPM Centre of Excellence in the functioning of the governance mechanisms, it is proposed to separate this factor as a key PG element.

BPM standards and methodologies are mainly based on reference models. They play an important role in end-to-end improving and managing business processes (Spanyi, 2010). The literature indicates that the BPM implementation success significantly depends on understanding, adaptation and skilful application (Jurczuk, 2019). The undertaken BPM methodology standardisation efforts are aimed at unifying initiatives in terms of methods, tools, meas-

Tab. 2. Core elements of process governance - frameworks review

\begin{tabular}{|c|c|c|c|c|c|}
\hline \multirow[b]{2}{*}{ REFERENCE MODEL/FRAMEWORK } & \multirow[b]{2}{*}{ 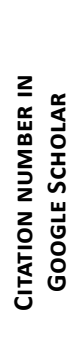 } & \multicolumn{4}{|c|}{ PROCESS GOVERNANCE CORE ELEMENTS } \\
\hline & & 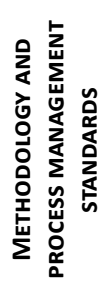 & 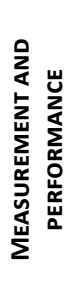 & 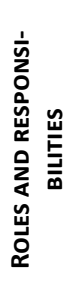 & 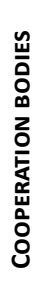 \\
\hline $\begin{array}{l}\text { BPM Six Core Elements model } \\
\text { (Rosemann \& De Bruin, 2005; Rosemann and } \\
\text { Vom Brocke, 2010) }\end{array}$ & 446 & $\mathrm{~F}$ & $\mathrm{~F}$ & $\mathrm{~F}$ & I \\
\hline $\begin{array}{l}\text { Process guidelines (book chapter) } \\
\text { (Jeston \& Nelis, 2014) }\end{array}$ & 1468 & $\mathrm{~F}$ & $\mathrm{~F}$ & $\mathrm{~F}$ & $\mathrm{~F}$ \\
\hline $\begin{array}{l}\text { Process Governance Framework } \\
\text { (Braganza \& Lambert, 2000) }\end{array}$ & 75 & 1 & $\mathrm{~F}$ & $\mathrm{~F}$ & 1 \\
\hline $\begin{array}{l}\text { Business Process Governance } \\
\text { (Kirchmer, 2017) }\end{array}$ & 66 & I & $\mathrm{F}$ & $\mathrm{F}$ & I \\
\hline
\end{tabular}

Description: $\mathrm{F}-$ fully covered, I - indirectly covered, $\mathrm{N}-$ non covered 
ures and indicators, process architecture and document templates. Richardson (2006) and Santana et al. (2011) emphasised that the use of a domain-appropriate and formalised methodology makes it possible to establish consistent rules for process management and to standardise the rules and forms of their description. Moreover, BPM standards refer to a set of guidelines with respect to the establishment and management process measures, issue resolution, reward, and remuneration structures (Rosemannn \& Vom Brocke, 2015).

Measuring the performance of business processes is fundamental from the perspective of their management and improvement. The fundamental role of this activity is to determine whether a business process meets the planned objectives (Kohlbacher \& Gruenwald, 2011). From the PG perspective, an important issue of process monitoring is the consistency of the process performance assessment and the established strategic objectives of the organisation. Whereby the process governance mechanisms in place should ensure access, collection of the required process metrics and linking them to performance criteria (Rosemannn \& Vom Brocke, 2015). It is also necessary to provide methodological support for the design, alignment of process measures (and measurement methods), and rules for feedback on measurement outcomes (Doebeli et al., 2011). These issues are closely linked to a consistent way of defining and allocating responsibility for this element of process governance (Kohlbacher \& Gruenwald, 2011; Christiansson \& Rentzhog, 2020).

The next PG element, i.e., roles and responsibilities, represents the entire range of BPM-related roles. While there is no agreement among researchers regarding the nomenclature and names of process roles themselves (ABPMP, 2013; Kettenbohrer, 2016; Hrabal et al., 2020), it is the importance of the human factor that is considered crucial for the successful management of business processes in an organisation (Kratzer et al., 2019; do Amaral Castro et al., 2020). From the perspective of BPM success, one of the most important process roles is undoubtedly the process owner (Ensslin et al., 2017; Danilova, 2018; Hrabal \& Tucek, 2018). Their responsibilities include designing, documenting and standardising processes.

A process owner also participates in activities related to performance management, process improvement and innovation. A very important issue in the context of consistency of cross-functional decision-making is, first of all, the necessity of formal decision-making empowerment of the process owner in the structure of the organisation (Bandara et al., 2019). Furthermore, the effectiveness of process governance mechanisms depends on its ability to manage and lead process teams and to communicate and manage stakeholders (Funke \& Reha, 2019). These tasks are performed within process teams and in cooperation with the BPM Centre of Excellence (or BPM Competence Centres or Business Processes Office) (Santana et al., 2011; Bitkowska, 2018; Hrabal et al., 2020).

Establishing a BPM Centre of Excellence (BPM $\mathrm{CoE}$ ) and process teams as a PG part within the organisation means to formalise the roles and responsibilities of business process stakeholders. According to several researchers (Richardson, 2006; Rosemann, 2015; Hammer, 2015; Bitkowska, 2018), the BPM CoE plays a key role in process governance. The BPM $\mathrm{CoE}$ should be the main source of support for process owners, providing guidance, knowledge transfer and data exchange. With that said, the portfolio of its service may vary widely (Rosemann, 2015, Jeston \& Nellis, 2014). The responsibilities of the BPM CoE generally include leading BPM, implementing the regulatory framework for BPM, offering project support, providing training, communication between process stakeholders and process management (Richardson, 2006; Hammer, 2015; Bitkowska, 2018).

The challenge of establishing a BPM CoE is its place in the structure of the organisation, which should be aligned with the operating conditions and the process maturity level of the enterprise (Christiansson \& Rentzhog, 2020). Bitkowska (2018) considered it a centralised and separated organisational unit. Markus and Jacobson (2015) considered it a unit forming a separated level of the organisation's decision-making hierarchy (a hierarchy approach). Furthermore, the $\mathrm{BPM} \mathrm{CoE}$ can operate through informal and formal lateral process stakeholder relationships (a horizontal approach). It is also possible for more than one BPM Centre of Excellence to operate within the structure of the organisation. The way the BPM CoE functions should ensure the coordination and management of BPM initiatives in the enterprise.

The core elements of process governance identified based on the literature review formed the basis for the analysis and synthesis of barriers to its implementation in an organisation. Their identification enabled some systematisation of the limitations and obstacles to the process governance mechanisms in an organisation and thus to the implementation of successful BPM initiatives. 


\section{METHODOLOGY AND RESEARCH PROCESS}

The identified core elements were the basis for defining barriers to process governance implementation in organisations. Based on the literature review results, an attempt was made to perform a cross-sectional analysis and then a synthesis of barriers to implementing process governance mechanisms. This task was performed using the idea of conceptual framework analysis (CFA) process proposed by Jabareen (2009). This qualitative method supports building a conceptual framework for phenomena that are linked to multidisciplinary bodies of knowledge. It refers to the methodology for developing a theoretical or conceptual framework based on the analysis of different data sources presented by Miles and Huberman (1994). The use of this methodology to identify PG barriers allows the existing literature to be synthesised without analysing primary data (Paré et al., 2015). The overview of the research process is given in Table 3.

The first phase of this research was dedicated to mapping and selecting the literature related to the research area. The sources of information were publications considering Business Process Management, Business Process Orientation (BPO), BPM critical success factors and BPM/BPO maturity, process governance, corporate and IT governance. In the next phase of the research process, a review of the collected literature resulted identifying potential barriers to the implementation of process governance in organisations. According to the applied methodology, in the next stage of the research process, the identified barriers were reviewed and classified (phase 2). The following step of the research (phase 3) involved the integration and grouping of the collected data using the PG core elements identified in the earlier step. The research process was concluded with the synthesis of the obtained analysis results (phase 4). The results of the study were the basis for the final conclusions and recommendations.

The suitability of such an approach is confirmed by work related to the identification of BPM success factors (Gabryelczyk, 2018), a social pattern of business process (Schoormann et al., 2019), and corporate governance (Bawazir et al., 2021).

\section{BARRIERS TO THE IMPLEMENTA- TION OF PROCESS GOVERNANCE - RESULTS AND DISCUSSION}

The potential barriers to implementing the governance process result from the cross-sectional analysis of the domain literature. According to the adopted methodology, identified barriers were verified, structured, and then mapped to the defined PG core elements. Tables 4-7 present a synthesis of the results of the conducted research in relation to each of the core elements.

One significant problem related to the lack of or ineffective process governance mechanisms is the failure to achieve the assumed goals of BPM implementation. The analysis of the identified PG barriers shows their polarisation around the issue of perception and the use of formalised methodologies related to the execution and integration of tasks within the whole Business Process Management Life-Cycle (Table 4). In this context, the passive transfer of BPM methodologies is a significant problem to process governance consistency. As Kelemen and Kostera (2002) pointed out, the lack of their internalisation may lead, under certain conditions, to the failure of the undertaken BPM initiatives. Kerpedzhiev et al. (2021) also pointed out that failure to consider the context of the use of BPM methods and tools can negatively affect the implementation of tasks derived

Tab. 3. Overview of the research process

\begin{tabular}{|c|l|l|}
\hline PHASE & \multicolumn{1}{|c|}{ CFA PHASE } & \multicolumn{1}{|c|}{ OBJECTIVE OF THE PHASE AS PER CFA } \\
\hline 1 & $\begin{array}{l}\text { Collecting, mapping and reading literature referring to } \\
\text { the research area }\end{array}$ & $\begin{array}{l}\text { Mapping the spectrum of multidisciplinary literature } \\
\text { regarding the business process governance } \\
\text { Studying and categorising selected papers }\end{array}$ \\
\hline 2 & $\begin{array}{l}\text { Identification and definition of potential barriers to the } \\
\text { process governance implementation }\end{array}$ & $\begin{array}{l}\text { Identification and understanding the background of po- } \\
\text { tential barriers of BPM implementation and governance }\end{array}$ \\
\hline 3 & $\begin{array}{l}\text { Integration of potential barriers to the process gover- } \\
\text { nance implementation }\end{array}$ & $\begin{array}{l}\text { Integration and grouping together potential barriers to } \\
\text { implementation of process governance }\end{array}$ \\
\hline 4 & Synthesis & $\begin{array}{l}\text { Synthesis barriers to implementation of process gover- } \\
\text { nance }\end{array}$ \\
\hline
\end{tabular}

Source: Elaborated by the author based on Jabareen, 2009. 
from the BPM Life Cycle. The unfamiliarity with or incomplete understanding of BPM methodologies and standards can result in inconsistent process governance in planning and organising BPM initiatives undertaken by the organisation. As noted by Bandara et al. (2009), the lack of knowledge and correct application of BPM methodologies and standards are among the significant barriers to process management success. The need for standardisation of BPM methodologies is also emphasised by Scheer and Klueckmann (2009) in the context of coordinating the work of individual process teams in an organisation. The lack of standards means that content can be interpreted differently, leading to decisions based on incorrect data. Considering the specificity of PG barriers in the area of methodology and process management standards (Table 4), their appearance may be due to the low level of necessary knowledge and skills of process stakeholders in this area. Deficiencies in BPM and process governance competencies may affect the quality of identifying customer needs, critical success factors, defining enterprise architecture and process architecture.

An adequate and consistent approach to documenting business processes is also an important PG barrier. The results of empirical studies indicate that, on the one hand, their documentation and modelling is a relatively well-known and applied practice among companies implementing BPM (Gazova et al., 2016; Paschek et al., 2018), while, on the other hand, inconsistencies of process documentation/models are a barrier to effective process management frequently reported by researchers (McCormack et al., 2009; Glavan et al., 2015). The non-compliance of processes with documentation reduces the value they create from both internal and external customer perspectives (Hashmi et al., 2018). Inconsistencies in process documentation can significantly affect how well it is understood and accepted by process stakeholders. As a result, this leads to a mismatch in the way processes are performed and degrades the effectiveness and efficiency of their management and the communication of process participants (Jurczuk, 2019). This problem is considered more extensively by researchers in the context of the process culture of organisations (Schmiedel et al., 2013; Štemberger et al., 2018).

A major challenge for the operation of PG mechanisms is also the standardisation of processes and their compliance with external regulations and standards. The dilemma between the need to formalise processes and the need to maintain their flexibility and ability to innovate is highlighted (Schäfermeyer et al., 2012; Schmiedel \& Vom Brocke, 2015; Wurm $\&$ Mendling, 2020). On the one hand, a tighter governance mechanism brings a more formalised processes documentation and training (Wurm

Tab. 4. Barriers to implementing process governance mechanisms - methodology and BPM standards

\begin{tabular}{|c|c|c|}
\hline CORE ELEMENT & GOVERNANCE BARRIERS & REFERENCE (CHOSEN) \\
\hline $\begin{array}{l}\text { Methodology } \\
\text { and BPM stan- } \\
\text { dards }\end{array}$ & 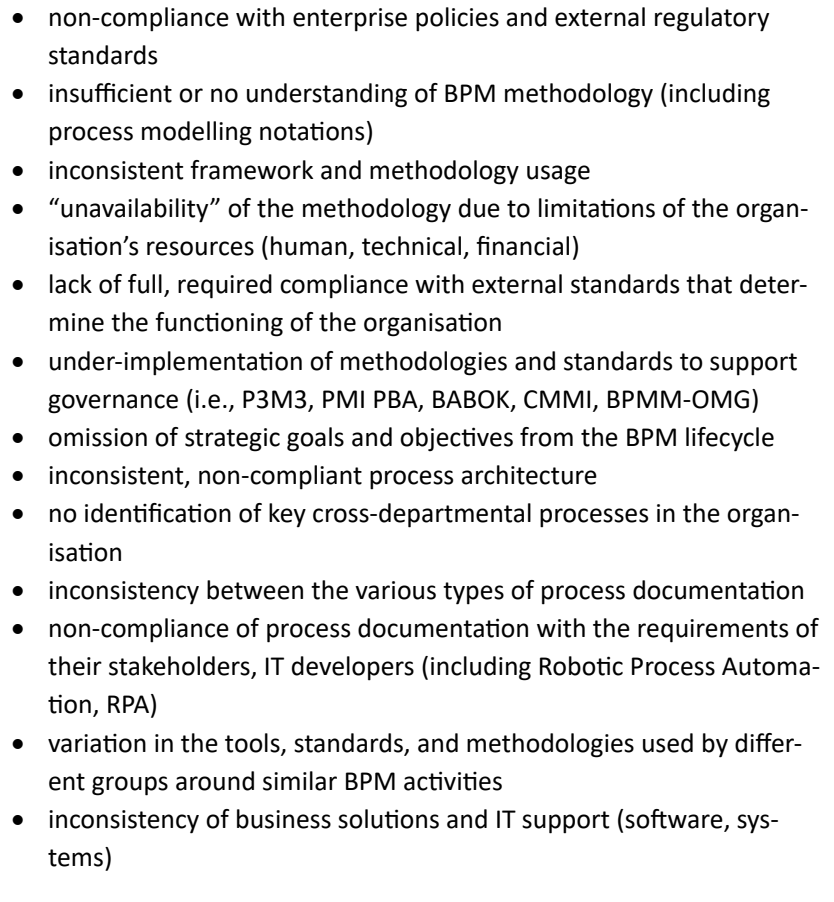 & $\begin{array}{l}\text { Kelemen \& Kostera, } 2002 \\
\text { Richardson, } 2006 \\
\text { Bhat \& Fernandez, } 2007 \\
\text { Bandara et al., } 2009 \\
\text { DeBruin, } 2009 \\
\text { Ko et al., } 2009 \\
\text { McCormack et al., } 2009 \\
\text { Scheer \& Klueckmann, } 2009 \\
\text { Santana et al., } 2011 \\
\text { Schäfermeyer et al., } 2012 \\
\text { Schmiedel et al., } 2013 \\
\text { Rosemannn \& Vom Brocke, } 2015 \\
\text { Hove et al., } 2015 \\
\text { Glavan et al., } 2015 \\
\text { Gazova et al., } 2016 \\
\text { Hashmi et al., } 2018 \\
\text { Paschek et al., } 2018 \\
\text { Štemberger et al., } 2018 \\
\text { Jurczuk, } 2019 \\
\text { Wurm \& Mendling, } 2020 \\
\text { Kerpedzhiev et al., } 2021\end{array}$ \\
\hline
\end{tabular}


\& Mendling, 2020), while on the other hand, the formalisation of processes may limit their flexibility and creativity and innovation of employees (Tregear, 2015). Kerpedzhiev et al. (2021) considered BPM capabilities in the context of digital development and indicated a barrier to the development of governance mechanisms, i.e., an underestimation of the role of standards and guidelines for data management.

Establishing process governance mechanisms for process performance is a multidimensional problem and requires considering aspects related to both strategic and operational management as well as human resources, organisational behaviour or information systems (Franco-Santos et al., 2007; Sangwa \& Sangwan, 2018). Process performance should be an integral part of corporate performance evaluation. In general, governance barriers related to measurement and performance may arise from an organisation's inability to adapt and apply a comprehensive process management methodology and a low level of process maturity and culture (Van Loy \& Devos, 2019; Schmiedel et al., 2020). The analysis of identified barriers to process governance (Table 5) showed that they revolve around two main aspects: design and measurement and reporting and information flows.

A key issue from the perspective of the occurrence of potential barriers to process governance mechanisms is to ensure that process measurement and monitoring is comprehensive, and that objectives and performance indicators are consistent (FrancoSantos et al., 2007; Eckerson, 2009; Enslin et al., 2017; Kirchmer, 2017). This should be an integral part of enterprise governance (Hove et al., 2015; Dominguez et al., 2019). It is noted that the usability of the measurement system is influenced by the quality of the evaluation criteria of the process measures themselves and their information potential, and the quality of the data captured (Khosravi, 2016). As with the previous PG core element, a significant barrier to measurement and performance is the low level of process competence of employees and an organisation's process culture that is not aligned with the circumstances (Schmiedel et al., 2013; Jurczuk, 2019). The lack of a well-developed process culture of an organisation may affect the attitudes of process stakeholders in identifying and responding to problems in processes and the reliability of information and data supporting process governance. A derivative of competence gaps and data quality may be the misinterpretation of metrics as well as measurement outputs. This may lead to unjustified adjustment activities resulting in unnecessary changes in the way processes are performed.
Moreover, their adjustment mechanism based on inconsistent metrics and unreliable and incomplete information may lead to discrepancies in the way processes are performed and organised. This is usually associated with a lack of critical analysis of the documentation in force in the enterprise prior to the introduction of changes to processes, which are assumed to lead to a reduction in their time and cost (Kohlbacher \& Gruenwald, 2011; Enslin et al., 2017). As a result, it may cause deregulation of processes and their implementation according to the own preferences of their performers and not according to the established rules.

PG barriers related to measurement and performance may also result from information overload and insufficient support of IT tools in the design and use of the process monitoring system, including visualisation of process performance evaluation results (Valenca et al., 2013; Rahimi et al., 2016; Dominguez et al., 2019). The consequence of such a state is the inconsistency of information that forms the basis of managerial decisions related to the current and future way of process execution and, consequently, the functioning of the organisation (Jurczuk, 2019). This constitutes a critical barrier to the proper functioning of governance process mechanisms.

Roles and responsibilities, according to many researchers (Spanyi, 2010; Doebeli et al., 2011; Hammer, 2015; Rosemann \& Vom Brocke, 2010), are a key element in activating process governance mechanisms in an organisation. As Hammer (2015) emphasised, the sustainable institutionalisation of BPM requires an appropriate division of responsibilities that ensure a holistic view of the relationships and impacts of business processes. Furthermore, it is important to ensure that the introduced division of roles and responsibilities does not turn into a new generation of horizontal silos (Hammer, 2015).

A review of ongoing research in this area has shown that the main constraints to the PG functioning include the lack of a process owner (Kohlbacher \& Gruenwald, 2011; Danilova, 2018; Hrabal \& Tucek, 2018 ) and the deficiency of or inadequately shared responsibility (Spanyi, 2010; Hammer, 2015; Rosemann \& Vom Brocke, 2010). Discussions of the barriers to the functioning of process governance in relation to the key role of the process owner in BPM emphasise that these arise from the lack of real decision-making authority (Vom Brocke et al., 2014; Danilova, 2018; Hrabal \& Tuĉek, 2018).

The effectiveness of PG mechanisms also depends on the place of the process owner in the hierarchy of 
Tab. 5. Barriers to implementing process governance mechanisms - measurement and performance

\begin{tabular}{|c|c|c|}
\hline CORE ELEMENT & GOVERNANCE BARRIERS & REFERENCE (CHOSEN) \\
\hline $\begin{array}{c}\text { Measurement } \\
\text { and performance }\end{array}$ & $\begin{array}{l}\text { - } \text { not recognizing the requirements of process stakeholders } \\
\text { - } \text { units/company } \\
\text { - } \text { undefined or ambiguous overarching organisational goals and corre- } \\
\text { - sponding Key Performance Indicators (KPIs) } \\
\text { - lack of vertical and horizontal integrity of process measurement systems } \\
\text { - lack of clear, effective rules and mechanisms to identify areas, processes } \\
\text { - lequiring improvement (risks, weaknesses) } \\
\text { - } \text { non-systematic measurement activities } \\
\text { - lack of feeding back mechanism into BPM planning stages } \\
\text { - misunderstanding of process evaluation results non-appropriate busi- } \\
\text { - ness processes performance review mechanisms } \\
\text { - ineffective or lack of reporting, process knowledge management system, } \\
\text { - } \text { misinformation acquisition, interpretation and enforcement of audit informa- } \\
\text { - lack of information on how objectives/business drivers are achieved } \\
\text { - non-sufficient IT support } \\
\text { - lack of precise rules for filtering and information flow } \\
\text { - non effective reward system }\end{array}$ & $\begin{array}{l}\text { Franco-Santos et al., } 2007 \\
\text { Eckerson, } 2009 \\
\text { Schmiedel et al., } 2014 \\
\text { Hove et al., } 2015 \\
\text { Hernaus et al., } 2016 \\
\text { Rahimi et al., } 2016 \\
\text { van der Aalst et al., } 2016 \\
\text { Sangwa \& Sangwan, } 2018 \\
\text { Dominguez et al., } 2019 \\
\text { Van Loy \& Devos, } 2019 \\
\text { Schmiedel et al., } 2020\end{array}$ \\
\hline
\end{tabular}

Tab. 6. Barriers to implementing process governance mechanisms - roles and responsibilities

\begin{tabular}{|c|c|c|}
\hline CORE ELEMENT & GOVERNANCE BARRIERS & REFERENCE (CHOSEN) \\
\hline $\begin{array}{l}\text { Roles } \\
\text { and responsibilities }\end{array}$ & $\begin{array}{l}\text { - undefined or inadequate division of tasks, responsibilities, and the } \\
\text { decision-making hierarchy in relation to the organisational structure } \\
\text { and process architecture (all its levels) } \\
\text { - lack of empowerment } \\
\text { - weak position or no appointment of process owners } \\
\text { - failure to define the scope of responsibilities and authority of pro- } \\
\text { cess owners } \\
\text { - lack of exchange of information regarding the reallocation of re- } \\
\text { sources, redefinition of process roles, and responsibilities of process } \\
\text { - performers } \\
\text { (functional) leadership and process coordination, including responsi- } \\
\text { bility for improving and managing the organisation's key processes } \\
\text { lack of rules and best practices for communicating the organisation's } \\
\text { strategy and business objectives }\end{array}$ & $\begin{array}{l}\text { Rosemann \& de Bruin, } 2005 \\
\text { Spanyi, } 2010 \\
\text { Doebeli et al., } 2011 \\
\text { Kohlbacher \& Gruenwald, } 2011 \\
\text { Valenca et al., } 2013 \\
\text { Nurdiani et al., } 2014 \\
\text { Hamer, } 2015 \\
\text { Reijers et al., } 2015 \\
\text { Hernaus et al., } 2016 \\
\text { Syed et al., } 2016 \\
\text { Kirchmer, } 2017 \\
\text { Hrabal \& Tuĉek, } 2018 \\
\text { Danilova, } 2018 \\
\text { Klun \& Trkman, } 2018 \\
\text { Bruccoleri et al., } 2019 \\
\text { Kratzer et al., } 2019\end{array}$ \\
\hline
\end{tabular}

the organisation (Markus \& Jacobson, 2015; Hrabal et al., 2020) and their leadership experience (Kohlbacher \& Gruenwald, 2011; Danilova 2018). The effectiveness of PG mechanisms may be affected by the issue of centralising or decentralising responsibilities of process ownership roles (Hrabal et al., 2020).

To avoid the basic barrier of process governance, which is the conflict of decision-making powers, it is recommended to create a new position in the organisational structure for the process owner independent of vertical divisions of responsibility (Markus
\& Jacobson, 2015, Hernaus et al., 2016). Moreover, the functioning of PG mechanisms may be limited by problems of resource competition or resource mismatch.

Therefore, issues of defining responsibility should be considered with the allocation of resources needed for BPM projects (Nurdiani et al., 2014; Jurczuk, 2019). However, as emphasised (Hammer, 2007; Hernaus et al., 2016), the position of the process owner should be defined and reviewed as the process maturity level of the organisation changes. 
The analysis of PG barriers related to roles and responsibilities has also shown that their underlying cause is the lack of an empowered process culture in the organisation, especially in terms of employee attitudes and behaviours, leadership or communication, and teamwork ability (Santos \& Alves, 2015; Schmiedel \& Vom Brocke, 2015). Potential constraints may result from the difficulty of performers to adapt to process-oriented work styles and principles, siloed employee mentality leading to the limited focus on cross-functional processes, lack of focus on systematic improvement and innovation, and lack of BPM communication strategies (Rosemann \& de Bruin, 2005; Klun \& Trkman, 2018). The process governance mechanisms are also adversely affected by the inability to work and make decisions collectively (Spanyi, 2003; Alibabaei et al., 2009). This problem is explored in the context of the "Abilene Paradox" (Bruccoleri et al., 2019). The occurring constraints in sharing and executing responsibilities are also linked to the lack of appropriate skills in methodologies supporting BPM implementation (Hove et al., 2015; Jurczuk, 2019). The lack of adequate methodological support may negatively affect the consistency of proceedings, knowledge transfer, consistency of documentation, and, thus, the behaviour and attitudes of process stakeholders and, as a result, process governance mechanisms.

Another barrier to the implementation of $\mathrm{PG}$ mechanisms is related to leadership problems. On the one hand, its quality reflects the willingness of the BPM leader to lead and take real responsibility for business processes and, on the other hand, the extent to which the necessary leadership skills are applied in business practice (Syed et al., 2016; Wipulanusat et al., 2017; Bruccoleri et al., 2019). Occurring barriers to this underlying background are usually related to the lack of or insufficient support of BPM initiatives undertaken by the company's governing body. It can also be linked to the lack of a multilevel communication system to ensure the consistency of the information needs network and the integrity of information sources (zur Muehlen \& Ho, 2006; Jurczuk, 2019). As Funke \& Reha (2019) and Kratzer et al. (2019) highlighted, a barrier to BPM implementation may be the lack of a people-oriented leadership style. Leadership issues also arise in the context of knowledge transfer and discrepancies in requirements and behaviours in subordinate-supervisor relationships (Syed et al., 2016; Kirchmer et al., 2015). In the era of digital technologies and prevailing digitalisation and automation of business processes (Kirchmer, 2017; Kratzer et al.,
2019; Kerpedzhiev et al., 2021), it is also worth paying attention to leadership barriers in the context of implementing technology changes in the organisation. This problem was recognised by Appelbaum et al. (1998), pointing to the legitimacy of changing the optics of the leader from technocratic to interpretive. Problems with sharing and executing responsibilities are also linked to the lack of appropriate skills in methodologies supporting BPM implementation (Hove et al., 2015; Jurczuk, 2019). The lack of adequate methodological support may negatively affect the consistency of proceedings, knowledge transfer, consistency of documentation, and, thus, the behaviour and attitudes of process stakeholders and, as a result, process governance mechanisms.

An important constraint for process governance mechanisms is the non-existent or inappropriately functioning BPM bodies, including the Centre of Excellence and process teams. In conjunction with the formally separated process roles (process owner, BPM manager), these constitute the basis for establishing governance bodies in the organisation (Jesus et al., 2018; Van Looy \& Devos, 2019). The identified barriers related to this core element are included in Table 7.

As Rosemann (2010) points out, organisations usually establish BPM Centres of Excellence only as their process maturity increases. This is a consequence of the process-driven development of the organisation (Hammer, 2015). Failure to establish a BPM CoE may be due to unwillingness to break the existing structure of authority's influence, fear of loss of power of individual functional units resulting from the implementation of a process approach to management (Jurczuk, 2019).

When analysing the barriers of process governance, it is worth noting the importance of the CoE for the success of BPM. Indeed, the main tasks of the Centres of Excellence include, as mentioned above, supporting the implementation and coordination of BPM projects, knowledge transfer and providing support in the field of BPM methodologies, technique, tools and strategy alignment and establishing a process-oriented culture in the organisation (Richardson, 2006; Bitkowska, 2018). The establishment of a BPM centre is primarily intended to eliminate obstacles associated with cross-departmental interaction, collaboration and, of course, communication with external/internal process participants. This is particularly important in the case of interdepartmental business process initiatives, which, due to the lack of a coordinating unit, often get bogged down in interdepartmental politics, disputes and misunderstandings 
Table 7. Barriers to implementing process governance mechanisms - cooperation bodies

\begin{tabular}{|c|c|c|}
\hline Core element & GOVERNANCE BARRIERS & REFERENCE (CHOSEN) \\
\hline $\begin{array}{l}\text { Governance bodies } \\
\text { and cooperation }\end{array}$ & $\begin{array}{l}\text { - lack of BPM Centres of Excellence (or BPM Competence Cen- } \\
\text { tres or Business Processes Office) } \\
\text { - position of BPM Centres in the organisation's structure is not } \\
\text { - ldjusted to the requirements/maturity level } \\
\text { - lack of adequate communication with managers regarding } \\
\text { - low integration } \\
\text { - traditional hierarchical thinking } \\
\text { - non-formalised structure and position of process team and } \\
\text { cross-departmental teams } \\
\text { - lack of effective communication between teams/groups of } \\
\text { - lack of a common language of communication and effective } \\
\text { communication between process stakeholders } \\
\text { - failure to establish rules and a level of formalisation of relations } \\
\text { with external partners } \\
\text { - failure to establish rules and a level of formalisation of relations } \\
\text { with internal process customers } \\
\text { lack of knowledge transfer - lack of understanding of the idea } \\
\text { and principles of process management and process orientation } \\
\text { at individual levels of the organisation }\end{array}$ & $\begin{array}{l}\text { Spanyi, } 2003 \\
\text { Richardson, } 2006 \\
\text { Korhonen, } 2007 \\
\text { Alibabaei et al., } 2009 \\
\text { Scheer \& Klueckmann, } 2009 \\
\text { Rosemann, } 2010 \\
\text { Santana et al., } 2011 \\
\text { Niehaves et al., } 2012 \\
\text { Tumbas et al., } 2013 \\
\text { Valenca et al., } 2013 \\
\text { Hamer, } 2015 \\
\text { Khosravi, } 2016 \\
\text { Syed et al., } 2016 \\
\text { Kirchmer, } 2017 \\
\text { Bitkowska, } 2018 \\
\text { Czarnecki, } 2018 \\
\text { Jesus et al., } 2018 \\
\text { Thennakoon et al., } 2018 \\
\text { Van Loy \& Devos, } 2019 \\
\text { Jurczuk, 2019 } \\
\text { Harmon \& Garcia, } 2020\end{array}$ \\
\hline
\end{tabular}

(Richardson, 2006). However, the findings of Harmon \& Garcia (2020) show that companies cite the lack of coordination of interdepartmental process changes and insufficient senior management support among the main obstacles to BPM implementation. The language of BPM experts, which is too hermetic, or the lack of a communication system to ensure the flow of information and to build trust and motivation, may also be a significant limitation to the PG functioning (Bitkowska, 2018; Van Looy \& Devos, 2019). These barriers may appear in the organisation precisely because of the lack of governance bodies, i.e., process owners, BPM leaders or BPM CoE. The failure of the BPM CoE to carry out its assigned tasks in terms of training and workshops may also be a source of process governance problems (Korhonen, 2007; Santana et al., 2011; Thennakoon et al., 2018). Overlooking proper staff preparation for changes in the way of working and too much focus on meeting external customer expectations may lead to competence gaps, which may cause resistance to change or misapplication of BPM support methodologies (Table 7).

The success of BPM is also determined by process teams (the Steering Process Committee, Process/Project Teams) which, in addition to the BPM CoE, constitute an important pillar of governance bodies. The main challenges of their functioning include the selection of the teams' membership and the way they are empowered, as well as the ability of their members to work as a team (Santana et al., 2011; Niehaves et al., 2012; Tumbas et al., 2013; Czarnecki, 2018). Santana et al. (2011) indicated that emerging barriers to BPM governance might be due to insufficient support of process team members by external consultants working with them. On the other hand, Czarnecki (2018) and Niehaves et al. (2012) indicated that process teams should also include people from outside the organisation. Moreover, researchers show that high team turnover (Valenca et al., 2013), often resulting from hiring staff from outsourcing companies (Santana et al., 2011), also has a negative impact on the functioning of PG mechanisms. When designing the structure of teams, one should also consider the possibility of certain conflicts related to their structure. Their substrates may be different attitudes of team members, competition between them for resources, and conflicts arising from service dependencies (Chong, 2007; Valenca et al., 2013; Tumbas et al., 2013; Khosravi, 2016). This is usually related to employees and managers belonging simultaneously to interdepartmental process teams and to relevant departments in the organisation. Emerging barriers related to the work of process teams may also result from the geographical dispersion of their members (Espinosa \& Boh, 2009; Thennakoon et al., 2018), poor integration, and the lack of informal meetings (Santana et al., 2011; Tum- 
bas et al., 2013). The occurrence of PG constraints, in this case, may be due to problems in understanding task dependencies or cognitive coordination (Espinosa \& Boh, 2009).

The functioning of governance mechanisms is also adversely affected by a lack of trust and fear of expressing opinions and by BPM leaders being too interventionist in decision-making or not involving customers and suppliers in process teams. A potential source of problems in implementing and governing BPM initiatives may be the lack of job satisfaction monitoring in governance bodies (Alibabaei et al., 2009; Syed et al., 2016; Jurczuk, 2019).

\section{CONCLUSIONS}

This paper reviews parts of the domain literature on Business Process Management to identify potential barriers of process governance mechanisms. The analysis and synthesis of the collected research data allow me to state that they are structured around four areas: culture, competencies, structures, and IT. Most process governance obstacles polarise around the competence gaps of the process stakeholders and the immaturity of the process culture of the enterprise. This is a problem resulting from both the availability of human resources and the perception of BPM projects as secondary (Doyle \& Seymour 2020). Competency and cultural barriers are mainly related to methodological errors and attitudes and behaviours of process stakeholders. Eliminating PG barriers from methodologies and standards is possible by ensuring consistency in the BPM tools, standards, and methods used by different teams in similar BPM activities (Bhat \& Fernandez, 2007).

Another group of constraints to process governance arises from the existing structure of the organisation. They are mainly related to the fear of losing the authority of the representatives of the functional areas when the management bodies are constituted. An important challenge in establishing process governance is also a coherent, sustainable division of roles and responsibilities that prevents ad hoc actions and the creation of new silo structures (Vom Brocke et al., 2014; Hammer, 2015). In addition, the occurrence of constraints in the functioning of governing bodies may be due to the weak position of BPM centres of excellence and/or their failure to fulfil their knowledge transfer and communication tasks. Inconsistencies in PG also result from the failure of governing bodies to properly coordinate BPM initiatives at both opera- tional and strategic levels. The PG limitations are relatively rarely associated with IT. They mainly refer to the lack of support of BPM systems in the decisionmaking process. It is also indicated that the development of technologies supporting BPM, including process intelligence, process mining, will cause the necessity of continuous adjustment and improvement of process governance mechanisms preventing the occurrence of constraints in their functioning.

The barriers to process governance mechanisms presented in the paper may contribute to a fuller understanding and thus to an insight into the challenges related to the BPM implementation. This is particularly important in the light of the increasing interest of organisations in the process approach to management. Thanks to the comprehensive approach to the identification of potential process governance barriers, the presented research results may contribute to the understanding of the reasons for failures in the implementation of BPM initiatives in organisations. Furthermore, the conducted synthesis of barriers to process governance can contribute to the development of a theoretical framework for Business Process Management.

Due to the changing circumstances of contemporary organisations, the mechanisms of process governance need to evolve, as does Business Process Management (Kerpedzhiev et al., 2021). Social, technology-driven changes in business realities will cause traditional governance mechanisms to become inadequate. The key challenge facing business leaders is, therefore, the ability to adapt to new market requirements and the expectations of process stakeholders. The complexity and multidimensionality of process governance aspects in the context of ongoing changes indicate the need for further research in this area. In the context of the observed changes in the way companies operate due to the ongoing pandemic situation, an interesting issue could be the analysis of the impact of remote working, virtualisation of teams and digital transformation on the mechanisms and instruments of process governance. Future research on distinct aspects of process governance would make an extremely valuable and comprehensive contribution to the body of knowledge on Business Process Management.

\section{LIMITATIONS}

Due to the character of the conducted research, the primary limitation of the presented results is the 
lack of empirical verification. Collecting the opinions of experts and BPM leaders responsible for implementing such initiatives in enterprises would allow the validation of the indicated barriers to the functioning of process governance mechanisms. The certain shortcoming of the presented synthesis is connected with the collection of literature referring to the research area. It would be worthwhile to apply a more formalised approach using criterion-based selection and rigorous critical evaluation for this purpose.

\section{ACKNOWLEDGEMENTS}

The publication of the article for the 11th International Conference on Engineering, Project and Production Management - EPPM2021 was financed in the framework of contract No. DNK/SN/465770/2020 by the Ministry of Science and Higher Education within the "Excellent Science" programme.

\section{1 \\ Ministry of Science \\ and Higher Education \\ Republic of Poland}

The research is carried out within the project "The FoF-Designer: Digital Design Skills for Factories of the Future (DigiFoF)", No. 601089-EPP-1-2018-1RO-EPPKA2-KA.

\section{LITERATURE}

Alibabaei, A., Bandara, W., \& Aghdasi, M. (2009). Means of achieving business process management success factors. In Proceedings of the 4th Mediterranean conference on information systems (pp. 1348-1363). Athens University of Economics and Business.

Appelbaum, S. H., St-Pierre, N., \& Glavas, W. (1998). Strategic organizational change: the role of leadership, learning, motivation and productivity. Management Decision 36(5), 289-301.

Association of Business Process Management Professionals (2013). Guide to the business process management common body of knowledge. BPM CBOK. Version 3.0 .

Bai, C., \& Sarkis, J. (2013). A grey-based DEMATEL model for evaluating business process management critical success factors. International Journal of Production Economics, 146(1), 281-292. doi: 10.1016/j. ijpe.2013.07.011

Bandara, W., Merideth, J., Techatassanasoontorn, A., Mathiesen, P., \& O’Neill, D. (2019). Mechanisms for creating successful BPM governance: Insights from Commonwealth Bank of Australia. In Proceedings of the 17th International Conference on Business Process Management 2019 Industry Forum, BPM2019IF,
CEUR Workshop Proceedings, 2428 (pp. 49-60). Sun SITE Central Europe.

Bawazir, H., Khayati, A., \& Abdul Majeed, F. (2021). Corporate governance and the performance of nonfinancial firms: the case of Oman. Entrepreneurship and Sustainability Issues, 8(4), 595. doi: 10.9770/ jesi.2021.8.4(36)

Bhat, J. M., \& Fernandez, J. (2007). Successful patterns of BPM governance: a case study. In BPM 2007 Workshop on Business Process Governance (pp. 16-26).

Bitkowska, A. (2018). Business process management centre of excellence as a source of knowledge. Business, Management and Education, 16(1), 121-132. doi: 10.3846/bme.2018.2190

Braganza, A., \& Lambert, R. (2000). Strategic integration: Developing a process-governance framework. Knowledge and Process Management, 7(3), 177-186. doi: 10.1002/1099-1441(200007/09)7:3<177::AIDKPM104>3.0.CO;2-U

Bruccoleri, M., Riccobono, F., \& Größler, A. (2019). Shared leadership regulates operational team performance in the presence of extreme decisional consensus/ conflict: evidences from business process reengineering. Decision Sciences, 50(1), 46-83. doi: 10.1111/ deci. 12325

Chong, S. (2007). Business process management for SMEs: an exploratory study of implementation factors for the Australian wine industry. Journal of Information Systems and Small Business, 1(1-2), 41-58.

Christiansson, M. T., \& Rentzhog, O. (2020). Lessons from the "BPO journey" in a public housing company: toward a strategy for BPO. Business Process Management Journal, 26(2), 373-404. doi: 10.1108/BPMJ-042017-0091

Czarnecki, C. (2018). Establishment of a central process governance organization combined with operational process improvements. In Business Process Management Cases (pp. 57-76). Cham: Springer.

Dallas, I., \& Wynn, M. T. (2014). Business process management in small business: a case study. In Information systems for small and medium-sized enterprises (pp. 25-46). Berlin, Heidelberg: Springer.

Danilova, K. B. (2018). Making process ownership work: Evidence from a global Delphi study. Knowledge and process management, 25(3), 153-167. doi: 10.1002/ kpm.1568

Davis, R., \& Brabänder, E. (2007). Roles and Responsibilities for BPM. ARIS Design Platform: Getting Started with BPM, Springer Science \& Business Media, 339-343.

de Boer, F. G., Müller, C. J., \& Caten, C. S. T. (2015). Assessment model for organizational business process maturity with a focus on BPM governance practices. Business Process Management Journal, 21(4), 908927. doi: 10.1108/BPMJ-11-2014-0109

De Bruin, T. (2009). Business process management: theory on progression and maturity. Doctoral dissertation, Queensland University of Technology.

do Amaral Castro, B. K., Dresch, A., \& Veit, D. R. (2020). Key critical success factors of BPM implementation: a theoretical and practical view. Business Process Management Journal, 26(1), 239-256. doi: 10.1108/ BPMJ-09-2018-0272 
Doebeli, G., Fisher, R., Gapp, R., \& Sanzogni, L. (2011). Using BPM governance to align systems and practice, Business Process Management Journal, 17(2), 184202. doi: $10.1108 / 14637151111122310$

Domínguez, E., Pérez, B., Rubio, A. L., \& Zapata, M. A. (2019). A taxonomy for key performance indicators management. Computer Standards \& Interfaces, 64, 24-40.

Doyle, C., \& Seymour, L. F. (2020). Governance Challenges Constraining Business Process Management: The Case of a Large South African Financial Services Corporate. Responsible Design, Implementation and Use of Information and Communication Technology, 12066, 325.

Eckerson, W. W. (2009). Performance management strategies. Business Intelligence Journal, 14(1), 24-27.

Elzinga, D. J., Horak, T., Lee, C. Y., \& Bruner, C. (1995). Business process management: survey and methodology. IEEE transactions on engineering management, 42(2), 119-128

Ensslin, L., Ensslin, S. R., Dutra, A., Nunes, N. A., \& Reis, C. (2017). BPM governance: a literature analysis of performance evaluation. Business Process Management Journal, 23(1), 71-86. doi: 10.1108/BPMJ-112015-0159

Espinosa, J. A., \& Boh, W. F. (2009, January). Coordination and governance in geographically distributed enterprise architecting: An empirical research design. In 2009 42nd Hawaii International Conference on System Sciences (pp. 1-10). IEEE.

Franco-Santos, M., Kennerley, M., Micheli, P., Martinez, V., Mason, S., Marr, B., ... \& Neely, A. (2007). Towards a definition of a business performance measurement system. International Journal of Operations \& Production Management, 27(8), 784-801.

Funke, C., \& Syed, R. (2019, January). The leadership influences in BPM lifecycle. In Proceedings of the 25th Americas Conference on Information Systems (AMCIS 2019), (pp. 1-9). Association for Information Systems.

Gabryelczvk, R. (2018, September). An exploration of BPM adoption factors: Initial steps for model development. In 2018 Federated Conference on Computer Science and Information Systems (FedCSIS), (pp. 761768). IEEE.

Gazova, A., Papulova, Z., \& Papula, J. (2016). The application of concepts and methods based on process approach to increase business process efficiency. Procedia Economics and Finance, 39, 197-205.

Glavan, L. M., Vukšić, V. B., \& Vlahović, N. (2015). Decision tree learning for detecting turning points in business process orientation: a case of Croatian companies. Croatian Operational Research Review, 207-224.

Hammer, M. (2015). What is business process management?. In Handbook on business process management 1 (pp. 3-16). Springer, Berlin, Heidelberg.

Harmon, P., \& Garcia, J. (2020). The state of business process management. BP Trends.

Hashmi, M., Governatori, G., Lam, H. P., \& Wynn, M. T. (2018). Are we done with business process compliance: state of the art and challenges ahead. Knowledge and Information Systems, 57(1), 79-133.
Hernaus, T., Vuksic, V. B., \& Štemberger, M. I. (2016). How to go from strategy to results? Institutionalising BPM governance within organisations. Business Process Management Journal, 22(1), 173-195.

Hove, M., von Rosing, G., \& Storms, B. (2015). Business Process Management Governance. The Complete Business Process Handbook. Body of Knowledge from Process Modelling to BPM, 1 (pp. 603-616). Elsevier.

Hrabal, M., \& Tuček, D. (2018). What Does it Mean to Own a Process: Defining Process Owners Competencies. FME Transactions, 46(1), 139.

Hrabal, M., Tuček, D., Molnár, V., \& Fedorko, G. (2020). Human factor in business process management: modeling competencies of BPM roles. Business Process Management Journal, 27(1), 275-305.

Iqbal, N., Nadeem, W., \& Zaheer, A. (2015). Impact of BPR critical success factors on inter-organizational functions: an empirical study. The Business \& Management Review, 6(1), 152.

Jabareen, Y. (2009). Building a conceptual framework: philosophy, definitions, and procedure. International Journal of Qualitative Methods, 8(4), 49-62. doi: 10.1177/160940690900800406

Jeston, J., \& Nellis, J. (2014). Business process management: practical guidelines to successful implementations. Routledge.

Jeston, J., \& Nelis, J. (2008). Management by process. A Roadmap to Sustainable Business Process Management. Routledge.

Jesus, L., Macieira, A., Karrer, D., \& Caulliraux, H. (2010). BPM center of excellence: the case of a Brazilian company. In Handbook on Business Process Management 2 (pp. 285-306). Berlin, Heidelberg: Springer.

Jurczuk, A. (2019). Wieloaspektowa identyfikacja i typologia źródeł niespójności procesów biznesowych [Multi-faceted identification and typology of business process inconsistency sources]. Oficyna Wydawnicza Politechniki Białostockiej.

Kelemen, M., \& Kostera, M. (2002). Introduction: travelling in time and space on the winds of the transition. In Critical Management Research in Eastern Europe (pp. 1-10). London: Palgrave Macmillan.

Kerpedzhiev, G., König, U. M., Röglinger, M., \& Rosemann, M. (2021). An Exploration into Future Business Process Management Capabilities in View of Digitalization. Business \& Information Systems Engineering, 63(2), 83-96.

Kettenbohrer, J. (2016). A Literature-Based Analysis of People's Roles in Business Process Management. Twentysecond Americas Conference on Information Systems, San Diego, 2016, 1-10.

Khosravi, A. (2016). Business process rearrangement and renaming. A new approach to process orientation and improvement. Business Process Management Journal, 22(1), 116-139. doi: 10.1108/BPMJ-02-2015-0012

Kirchmer M., Franz, P., \& von Rosing M. (2015). The Chief Process Officer: An Emerging Top Leadership Role. In The Complete Business Process Handbook, (pp. 343-348). Waltham: Elsevier.

Kirchmer, M. (2017). High Performance Through Business Process Management: Strategy Execution in a Digital World. Springer. 
Klun, M., \& Trkman, P. (2018). Business process management-at the crossroads. Business Process Management Journal, 24(3), 786-813.

Ko, R. K., Lee, S. S., \& Lee, E. W. (2009). Business process management (BPM) standards: a survey. Business Process Management Journal, 15(5), 744-791. doi: $10.1108 / 14637150910987937$

Kohlbacher, M., \& Gruenwald, S. (2011). Process orientation: conceptualization and measurement. Business Process Management Journal, 17(2), 267-283. doi: $10.1108 / 14637151111122347$

Korhonen, J. J. (2007). On the Lookout for Organizational Effectiveness - Requisite Control Structure in BPM Governance. Paper presented in 1st Business Process Governance, WoGO'2007.

Kratzer, S., Lohmann, P., Roeglinger, M., Rupprecht, L., \& zur Muehlen, M. (2019). The role of the chief process officer in organizations. Business Process Management Journal, 25(4), 688-706.

Markets and Markets (2020). Business Process Management Market. Global Forecast to 2025. Retrieved from www.marketsandmarkets.com.

Markus, M. L., \& Jacobson, D. D. (2015). Business process governance. In Handbook on business process management 2 (pp. 331-332). Berlin, Heidelberg: Springer.

McCormack, K., Willems, J., Bergh, J. V. D., Deschoolmeester, D., Willaert, P., Štemberger, M. I., \& Vlahovic, N. (2009). A global investigation of key turning points in business process maturity. Business Process Management Journal, 15(5), 792-815. doi: 10.1108/14637150910987946

Miles, M. B., \& Huberman, A. M. (1994). Qualitative data analysis: An expanded sourcebook (2nd ed.). Newbury Park, CA: Sage.

Malinova, M., Hribar, B., \& Mendling, J. (2014). A framework for assessing BPM success, Proceedings of the European Conference on Information Systems (ECIS) 2014, Tel Aviv, Israel, June 9-11.

Zur Muehlen, M. Z., \& Ho, D. T. Y. (2006). Risk management in the BPM lifecycle. In BPM 2005 Workshops, LNCS 3812 (pp. 454-466). Berlin, Heidelberg: Springer-Verlag.

Niehaves, B., Plattfaut, R., \& Becker, J. (2012). Business process governance: a comparative study of Germany and Japan. Business Process Management Journal, 18(2), 347-371. doi: 10.1108/14637151211225234

Nurdiani, I., Fricker, S., \& Börstler, J. (2014). Towards understanding how to build strategic flexibility of an IT organization. In IASTED-810: Software Engineering/811: Parallel and Distributed Computing and Networks/816: Artificial Intelligence and Applications. Acta Press.

Paré, G., Trudel, M. C., Jaana, M., \& Kitsiou, S. (2015). Synthesizing information systems knowledge: A typology of literature reviews. Information \& Management, 52(2), 183-199.

Paschek, D., Ivascu, L., \& Draghici, A. (2018). Knowledge management-the foundation for a successful business process management. Procedia-Social and Behavioral Sciences, 238, 182-191. doi: 10.1016/j.sbspro.2018.03.022
Rahimi, F., Møller, C., \& Hvam, L. (2016). Business process management and IT management: The missing integration. International Journal of Information Management, 36(1), 142-154. doi: 10.1016/j.ijinfomgt.2015.10.004

Reijers, H. A., Vanwersch, R. J. B., Vanderfeesten, I., \& Rietzschel, E. F. (2015). Improving business processes: does anybody have an idea?. Lecture Notes in Computer Science, 2015(9253), 3-18.

Richardson, C. (2006). Process governance best practices: Building a BPM center of excellence. Business Process Trends, 1-6.

Rosemann, M. (2015). The service portfolio of a BPM center of excellence. In Handbook on Business Process Management 2 (pp. 381-398). Berlin, Heidelberg: Springer.

Rosemann, M., \& De Bruin, T. (2005). Towards a business process management maturity model. In ECIS 2005 Proceedings of the Thirteenth European Conference on Information Systems (pp. 1-12). Verlag and the London School of Economics.

Rosemann, M., \& Vom Brocke, J. (2010). The Six Core Elements of Business Process Management. In Handbook on Business Process Management 1 (pp. 107122). Berlin, Heidelberg: Springer.

Sangwa, N. R., \& Sangwan, K. S. (2018). Development of an integrated performance measurement framework for lean organizations. Journal of Manufacturing Technology Management, 29(1), 41-84.

Santana, A. F. L., Alves, C. F., Santos, H. R. M., \& Felix, A. D. L. C. (2011). BPM governance: an exploratory study in public organizations. In Enterprise, Business-Process and Information Systems Modeling (pp. 46-60). Berlin, Heidelberg: Springer.

Santos, H. R. M., \& Alves, C. (2017). A2BP: A Method for Ambidextrous Analysis of Business Process. In ICEIS, 3 (pp. 227-238).

Schäfermeyer, M., Rosenkranz, C., \& Holten, R. (2012). The impact of business process complexity on business process standardization. Business \& Information Systems Engineering, 4(5), 261-270.

Scheer, A. W., \& Klueckmann, J. (2009). BPM 3.0. In: Dayal U., Eder J., Koehler J., Reijers H.A. (eds) Business Process Management. BPM 2009. Lecture Notes in Computer Science, 5701. Berlin, Heidelberg: Springer. doi: 10.1007/978-3-642-03848-8_2

Schmiedel, T., Recker, J., \& Vom Brocke, J. (2020). The relation between BPM culture, BPM methods, and process performance: Evidence from quantitative field studies. Information \& Management, 57(2), 103175.

Schmiedel, T., \&Vom Brocke, J. (2015). Business Process Management: Potentials and Challenges of Driving Innovation. BPM-Driving Innovation in a Digital World, 3-16.

Schmiedel, T., Vom Brocke, J., \& Recker, J. (2014). Development and validation of an instrument to measure organizational cultures' support of Business Process Management. Information \& Management, 51(1), 4356. doi: 10.1016/j.im.2013.08.005

Schmiedel, T., Vom Brocke, J., \& Recker, J. C. (2013). Which cultural values matter to business process management? Results from a global Delphi study. Business 
Process Management Journal, 19(2), 292-317. doi: 10.1108/14637151311308321

Schoormann, T., Kutzner, K., Pape, S., \& Knackstedt, R. (2019). Elevating Social Sustainability in Business Processes: A Pattern-Based Approach. In Proceedings of the International Conference on Information Systems (ICIS 2019), Munich, Germany.

Spanyi, A. (2003). Business Process Management is a Team Sport - Play It to Win. Tampa: Anclote Press.

Spanyi, A. (2010). Business Process Management Governance. In Handbook on business process management 2 (pp. 223-238). Berlin, Heidelberg: Springer.

Štemberger, M. I., Buh, B., Glavan, L. M., \& Mendling, J. (2018). Propositions on the interaction of organizational culture with other factors in the context of BPM adoption. Business Process Management Journal, 24(2), 425-445. doi: 10.1108/BPMJ-022017-0023

Syed, R., Bandara, W., French, E., \& Stewart, G. (2016). The status of research on leadership in business process management: A call for action. In Proceedings of the 30th Annual Australian New Zealand Academy of Management (ANZAM) Conference (pp. 1-15). Australian New Zealand Academy of Management.

Thennakoon, D., Bandara, W., French, E., \& Mathiesen, P. (2018). What do we know about business process management training? Current status of related research and a way forward. Business Process Management Journal, 24(2), 478-500. doi: 10.1108/BPMJ-092016-0180

Tregear, R. (2015). Business process standardization. In Handbook on Business Process Management 2 (pp. 421-441). Berlin, Heidelberg: Springer.

Trkman, P. (2010). The critical success factors of business process management. International Journal of Information Management, 30(2), 125-134. doi: 10.1016/j. ijinfomgt.2009.07.003

Valenca, G., Alves, C. F., Santana, A. F. L., de Oliveira, J. A. P., \& Santos, H. R. M. (2013). Understanding The Adoption Of BPM Governance In Brazilian Public Sector. ECIS 2013 Completed Research, 56.

Van Looy, A., \& Devos, J. (2019). A roadmap for (un) successful BPM: positivist case studies. Business Process Management Journal, 25(5), 1164-1190. doi: 10.1108/ BPMJ-04-2017-0083

Vom Brocke, J., Schmiedel, T., Recker, J., Trkman, P., Mertens, W., \& Viaene, S. (2014). Ten principles of good business process management. Business Process Management Journal, 20(4), 530-548.

Von Rosing, M., Laurier, W., \& Polovina, S. (2015). The BPM ontology. In The complete business process handbook (pp. 101-121). Elsevier.

Wipulanusat, W., Panuwatwanich, K., \& Stewart, R. A. (2017). Exploring leadership styles for innovation: an exploratory factor analysis. Engineering Management in Production and Services, 9(1), 7-17. doi: 10.1515/ emj-2017-0001

Wurm, B., \& Mendling, J. (2020). A Theoretical Model for Business Process Standardization. In International Conference on Business Process Management (pp. 281-296). Cham: Springer. 